\title{
Inflation Illusion and the Taylor Principle: An Experimental Study
}

\author{
Wolfgang J. Luhan* Johann Scharler ${ }^{\dagger}$
}

\begin{abstract}
We develop a simple experimental setting to evaluate the role of the Taylor principle, which holds that the nominal interest rate has to respond more than one-for-one to fluctuations in the inflation rate to exert a stabilizing effect. In our setting, the average inflation rate fluctuates around the inflation target if the computerized central bank obeys the Taylor principle. If the Taylor principle is violated, the average inflation rate persistently deviates from the target. These deviations from the target are less pronounced, if inflation rates cannot be as readily observed as nominal interest rates. This result is consistent with the interpretation that subjects underestimate the influence of inflation on the real return to savings if the inflation rate is only observed ex post.
\end{abstract}

Key words: Taylor principle, Interest Rate Rule, Inflation Illusion, Laboratory Experiment

JEL codes: E30, E52, C90

\footnotetext{
${ }^{*}$ Corresponding author: Ruhr-Universität Bochum, Institute for Macroeconomics \& Bochum Lab for Experimental Economics (RUBex), Universitaetsstrasse 150, 44801 Bochum, Germany, Phone +49 15774503569 , e-mail: wolfgang.luhan@rub.de

${ }^{\dagger}$ University of Innsbruck, Department of Economics, Universitaetsstrasse 15, A-6020 Innsbruck, Austria, Phone: +43512507 7357, e-mail: johann.scharler@uibk.ac.at.
} 


\section{Introduction}

Research on interest rate rules indicates that the strength of the feedback from the inflation rate to the nominal interest rate plays a crucial role for macroeconomic outcomes. The intuition is straight-forward: suppose that the inflation rate increases. If the central bank adjusts the nominal interest rate less than one-for-one, then the real interest rate declines, which stimulates aggregate demand resulting in even more inflationary pressure. Thus, monetary policy can exert a stabilizing influence only if it adjusts the nominal interest rate sufficiently to offset the influence of the inflation rate on the real interest rate. This proposition, which is known as the Taylor principle, is obtained in many models featuring interest rate rules. In New Keynesian Dynamic Stochastic General Equilibrium (DSGE) models, for instance, the Taylor principle ensures the determinacy of the rational expectations equilibrium. If the Taylor principle is violated, the equilibrium is indeterminate and fluctuations arising from self-fulfilling expectations may occur in this class of models (see, e.g., Woodford, 2003).

Empirically, the view that the Taylor principle plays a decisive role is supported by evidence indicating that major central banks have started to follow interest rate rules that satisfy the Taylor principle in the early 1980s, whereas inflationary pressure was accommodated to a larger extent prior to the 1980s (see, e.g., Judd and Rudebush, 1998; Clarida et al., 1998, 2000). Since this regime change in monetary policy roughly coincides with the beginning of the Great Moderation period in the mid 1980s, which is characterized by stable output growth and steadily low inflation, it appears that the Taylor Principle is indeed crucial. ${ }^{1}$

In this paper, we explore the role of the Taylor principle for inflation outcomes in a simple experimental setting: subjects repeatedly make two-period consumption and savings decisions and these decisions influence inflation dynamics via a Phillips curve relationship. A computerized central bank sets the interest rate according to an interest rate rule and aims at implementing an inflation target. To evaluate the Taylor principle in this setting, we vary the strength of the feedback from inflation to the interest rate across treatments.

The experimental method offers the advantage that we do not have to impose any behavioral assumptions. In fact, we are able to test whether subjects in the lab act in line with

\footnotetext{
${ }^{1}$ However, this view has also been questioned. Orphanides (2004) estimates interest rate rules with real-time data and finds that the Taylor principle was satisfied before and after 1980. In addition, several studies argue that low inflation rates and reduced business cycle volatility are not due to better monetary policy but rather the result of other factors such as structural change (see, e.g., Blanchard and Simon, 2001; Dynan et al., 2006; Davis and Kahn, 2008) or simply a reduction in the size of the shocks hitting the economy (see, e.g., Ahmed et al., 2004; Stock and Watson, 2005).
} 
the main behavioral assumption underlying the Taylor principle, namely, that intertemporal decisions are governed by the real interest rate. While this behavior is implicitly assumed in standard macroeconomic models, a number of contributions document that decisions are frequently subject to money illusion, which refers to a disposition to think in nominal rather than in real terms. ${ }^{2}$ Similarly, with respect to intertemporal decision making, people may be subject to inflation illusion; that is, they may neglect the effect of inflation on the real return on savings and perceive the nominal interest rate to be the real return. ${ }^{3}$ This type of behavior can have important implications for monetary policy. If, for instance, the nominal interest rate is more relevant for aggregate demand than the inflation rate, then the Taylor principle ceases to be a necessary requirement for stability, a point that is also emphasized by Fair (2005).

Another advantage of the experimental setting is that we are able to isolate the impact of the interest rate by ruling out any other influences. Hence, we can focus on the interest rate channel of the monetary transmission mechanism, which is strongly emphasized in the standard New Keynesian model.

We find that the inflation rate fluctuates around the inflation target if the computerized central bank sets the nominal interest rate in line with the Taylor principle. If, in contrast, the Taylor principle is violated, the inflation rate deviates persistently from the target rate. Nevertheless, these deviations are substantially smaller than expected in settings in which subjects can only observe the nominal interest rate and have to infer the inflation rate when making decisions. Since inflation rates can only be observed ex post in reality, this is the empirically relevant case.

We show that the reason for this result is that although people understand the influence of inflation on the real return on savings, the inflation rate is fully taken into account only if it can be readily observed. If the inflation rate cannot be observed ex ante, people base their decisions to a larger extent on the nominal interest rate. While the computational and cognitive costs are still relatively minor in the treatments in which the inflation rate has to be inferred, subjects over-emphasize the nominal interest rate over the inflation rate.

There are only few studies examining monetary policy issues using lab experiments. Peterson (2012) and Peterson and Krystov (2013) study experimental implementations of the New

\footnotetext{
${ }^{2}$ See Fisher (1928) for a seminal discussion of money illusion. Experimental studies of money illusion include Tyran (2007), Fehr and Tyran (2001), and Petersen and Winn (2014).

${ }^{3}$ Modigliani and Cohn (1979) argue that this type of behavior can lead to deviations of asset prices from fundamentals. See also Campbell and Vuolteenaho (2004), Piazzesi and Schneider (2008), and Brunnermeier and Julliard (2008).
} 
Keynesian model, which also motivates our setting, and Orland and Roos (2013) provide an experimental evaluation of the New Keynesian Phillips curve. Engle-Warnick and Turdaliev (2010) and Noussair et al. (2011) investigate interest rate setting in an experimental economy. These last two contributions explore the behavior of human central bankers in a computerized economy and find that subjects behave largely in line with the Taylor principle. Our focus, in contrast, lies on the interaction between human subjects with a computerized central bank. ${ }^{4}$ Pfajar and Zakelj (2011) and Assenza et al. (2011) study how the design of interest rate rules influences the formation of expectations in an experimental New Keynesian model economy. They find that inflation expectations are heterogeneous and that the design of the interest rate rule influences the stability of the inflation rate, since different rules provide different amounts of feedback for subjects. In constrast to these two papers, we abstract from the formation of expectations and focus on the consequences of inflation illusion. ${ }^{5}$

The remainder of the paper is structured as follows: Section 2 discusses the theoretical basis of our experimental investigation and briefly reviews the related literature. Section 3 presents the experimental design and procedure and discusses the treatments that we implement. In Section 4, we present our results, and Section 5 concludes the paper.

\section{Illustrating the Taylor Principle}

To illustrate the idea that the strength of the feedback from inflation to the nominal interest rate has a crucial influence on macroeconomic stability, consider a simple model adopted from Taylor (1999):

$$
\begin{gathered}
Y_{t}=-a\left(R_{t}-\pi_{t}\right), \\
\pi_{t}=\pi_{t-1}+b Y_{t-1}, \\
R_{t}=\delta \pi_{t},
\end{gathered}
$$

where $a>0, b>0$ and $\delta>0 . Y_{t}$ is the output gap, $R_{t}$ is the nominal interest rate, and $\pi_{t}$ denotes the inflation rate. Equation (1) is an IS relationship, equation (2) is a Phillips curve, and equation (3) is a simple interest rate rule that describes the behavior of the central bank.

For this model, it is easy to see that stability requires the Taylor principle to be satisfied: $\delta>1$. Suppose that the inflation rate increases. If $\delta>1$, then the central bank increases the

\footnotetext{
${ }^{4}$ Noussair et al. (2011) also implement treatments in which the interest rate rule is exogenously imposed. However, the interest rate rule always obeys the Taylor principle in these treatments.

${ }^{5}$ Bao et al. (2013) distinguish between forecasting and optimizing. According to this distinction, we rely on a learning-to-optimize design.
} 
nominal interest rate sufficiently to also increase the real interest rate, $R_{t}-\pi_{t}$. The higher real interest rate lowers aggregate demand according to equation (1), which puts downward pressure on inflation according to equation (2). By reacting sufficiently strongly to inflationary pressure, the central bank can offset the initial increase in inflation by contracting demand. If $\delta<1$ the increase in inflation actually results in a lower real interest rate, which in turn stimulates aggregate demand and leads to even stronger upward pressure on inflation rendering the system unstable.

In New Keynesian DSGE models, equation (1) is replaced with a forward-looking IS relationship derived from the solution to the intertemporal optimization problem of the representative household (see, e.g., Clarida et al., 1999; Woodford, 2003, for detailed discussions):

$$
Y_{t}=-a\left(R_{t}-E_{t} \pi_{t+1}\right)+E_{t} Y_{t+1}
$$

where $E_{t}$ denotes the expectation conditional on information available at time $t$. Equation (2) is replaced with the forward-looking New Keynesian Phillips curve, which is derived from the price-setting behavior of monopolistically competitive firms:

$$
\pi_{t}=c E_{t} \pi_{t+1}+d Y_{t}
$$

where $c>0$ and $d>0$. The main difference between equations (1) and (2) and their New Keynesian counterparts is that the latter contain conditional expectations of future output and inflation. It is well known that in this class of forward-looking models, the Taylor principle guarantees the determinacy, that is, local uniqueness and stability, of the rational expectations equilibrium. ${ }^{6}$

Note that in the models discussed here, aggregate demand depends either on the real interest rate, $R_{t}-\pi_{t}$ in equation (1), or on the expected real interest rate, $R_{t}-E_{t} \pi_{t+1}$, in equation (4). Thus, both types of models impose variants of the Fisher equation, which boils down to the behavioral assumption that agents take the inflation rate appropriately into account when they calculate the real return on savings. However, agents may, for instance, suffer from inflation illusion, and neglect the effect of inflation on the real return on savings. In this case, even a value of $\delta$ below unity may be consistent with stability, since it may suffice to stabilize the nominal interest rate in order to stabilize demand. In contrast, if agents perceive the effect of

\footnotetext{
${ }^{6}$ In addition to the implications for equilibrium determinacy, Bullard and Mitra (2002) show that the rational expectations equilibrium in the New Keynesian model is learnable in the sense of expectational stability if the Taylor principle holds. While this result puts additional emphasis on the role of the Taylor principle for stability, Duffy and Xiao (2011) find that it does not necessarily apply when capital investment is incorporated. Arifovic et al. (2013) find that the Taylor Principle is not necessary for convergence with evolutionary learning agents.
} 
inflation on the real return to be stronger than it actually is, the standard Taylor principle may be insufficient since a proportional adjustment of the nominal interest rate may not stabilize the perceived real interest rate. Agents may, for instance, overestimate the undesirable effects of inflation as the result of the memory of high inflation episodes as it is well known that opinions about the adverse effects of inflation are influenced by past experience of high inflation episodes (see, e.g. Shiller, 1997; Ehrmann and Tzamourani, 2012).

Thus, it is not clear whether the Taylor principle remains a sufficient, or even necessary condition for stability under alternative behavioral assumptions. We summarize our conjectures as follows: ${ }^{7}$ The Taylor principle is necessary and sufficient to stabilize inflation around the target if subjects calculate the real return on savings according to the Fisher equation. If subjects are prone to inflation illusion, the Taylor principle is still sufficient, but no longer necessary. If, in contrast, subjects overestimate the influence of inflation on the real return, an interest rate rule that satisfies the Taylor principle may not be sufficient to stabilize the perceived real interest rate and lead to instability. ${ }^{8}$

In the next section, we describe an experimental setup that allows us to explore these issues.

\section{Experimental Design and Procedure}

In this section we describe our experimental design. Rather than implementing a specific model in a laboratory environment, we aim at designing a setup which is as simple as possible while still incorporating those features that are essential for our research question.

Although the Taylor principle is generally discussed in infinite horizon models, we study the influence of real and nominal factors on consumption and savings decisions, and the resulting inflation dynamics, in a two-period setting. Since we are not primarily interested in issues related to intertemporal optimization, we can simplify the subjects' task by explicitly ruling out complications arising from, for example, long planning horizons. ${ }^{9}$

\footnotetext{
${ }^{7}$ Appendix A provides a formal discussion of the determinacy properties of a variant of the New Keynesian model that incorporates inflation illusion.

${ }^{8}$ While we focus on inflation illusion, the Taylor principle may generally neither be necessary nor sufficient for determinacy in more elaborated versions of the model, such models incorporating, for instance, more general interest rate rules (see, e.g., Woodford, 2003), rule-of-thumb consumers (Galí et al., 2004), capital investment (Carlstrom and Fuerst, 2005; Sveen and Weinke, 2007), openness (De Fiore and Liu, 2005), or switches in the interest rate rule (Davig and Leeper, 2007). Depending on the specific formulation of the model, modified versions of the Taylor principle apply.

${ }^{9} \mathrm{~A}$ number of authors experimentally examine intertemporal decision making in more general settings and document deviations from theoretical predictions (see, e.g., Hey and Dardanoni, 1988; Noussair and Matheny, 2000; Lei and Noussair, 2002; Ballinger et al., 2003; Carbone and Hey, 2004).
} 


\subsection{Experimental Design}

Each treatment of the experiment comprises $\tau=1, \ldots, 20$ rounds and each round consists of two periods $t=1,2$. In each round, each subject $i=1, \ldots, N$ has to solve a two-period decision problem: In the first period of each round, subjects receive a nominal endowment of 100 units of the experimental currency. This endowment can be exchanged for consumption goods at a price $P_{\tau, 1}$ in the first period of round $\tau$, or saved and (automatically) exchanged in the second period of the round at a price of $P_{\tau, 2}$. Everything that is not used to buy consumption goods in the first period earns a nominal interest rate of $R_{\tau}$ percent between periods 1 and 2 of round $\tau$. So consumption of subject $i$ in the second period is $C_{i, \tau, 2}=\left(100-C_{i, \tau, 1}\right)\left(1+R_{\tau}\right) / P_{\tau, 2}$, where $C_{i, \tau, 1}$ is the subjects' consumption in the first period. The subjects' decision problem is to choose consumption in the first period of each round to maximize total consumption in each round: $C_{i, \tau}=C_{i, \tau, 1}+C_{i, \tau, 2}$. Note that the endowment cannot be stored or transferred across rounds.

With this set-up we are able to study consumption decisions in a rather stationary environment, since subjects face the same decision problem in each round. While this setting is simple and easy to explain in the instructions, we are still able to to focus on how subjects respond to changes in the nominal interest rate and in the inflation rate. In other words, we are able to isolate a behavioral mechanism underlying the Taylor principle while preserving a simple structure.

Although consumption decisions are independent across rounds, the inflation rate between the two periods of round $\tau$, denoted by $\pi_{\tau}=P_{\tau, 2} / P_{\tau, 1}-1$, depends on average consumption in the first period of round $\tau-1$. This assumption allows us to analyze longer-run, inter-round inflation dynamics, despite the fact that subjects solve intra-round decision problems.

Inflation is determined as

$$
\pi_{\tau}=\bar{\pi}+\theta\left(\frac{1}{N} \sum_{i=1}^{N} C_{i, \tau-1,1}-\bar{C}\right)+\epsilon_{\tau}
$$

where $\frac{1}{N} \sum_{i=1}^{N} C_{i, \tau-1,1}$ is average consumption in the first period of round $\tau-1 . \bar{\pi}$ is the rate of inflation that prevails if $\frac{1}{N} \sum_{i=1}^{N} C_{i, \tau-1,1}=\bar{C}$. Equation (6) represents a Phillips Curve relationship and captures, in a simple way, the idea that aggregate consumption demand influences inflation. The parameter $\theta$ determines how strongly inflation responds to the deviation of average first-period consumption in the previous round from $\bar{C}$. We include an exogenous shock to the inflation rate, $\epsilon_{\tau}$, which helps to make the link between aggregate consumption and in- 
flation less salient in some of our treatments, since inflation illusion, in the sense that subjects overemphasize the nominal interest rate relative to the inflation rate, may be more prevalent in such a setting. The shock is uniformly distributed with an expected value of zero.

When setting the interest rate for round $\tau$, the central bank observes consumption in aggregate terms in round $\tau-1$, but not the realization of the shock for the current period. Since the shock has an unconditional mean of zero, the computerized central banks expects $\tilde{\pi}_{\tau}=\bar{\pi}+\theta\left(\frac{1}{N} \sum_{i=1}^{N} C_{i, \tau-1,1}-\bar{C}\right)$ to be the inflation rate for round $\tau$, given the information available at the beginning of round $\tau$. Based on $\tilde{\pi}_{\tau}$, the nominal interest rate is determined by the computerized central bank according to the interest rate rule

$$
R_{\tau}=\bar{R}+\delta\left(\tilde{\pi}_{\tau}-\bar{\pi}\right)
$$

Here, the central bank increases the interest rate above $\bar{R}$ if the inflation rate is greater than $\bar{\pi}$ and vice versa. So the central bank targets the rate of inflation that prevails if average consumption is equal to $\bar{C}$.

To summarize, in our baseline treatments, the timing of events is as follows: First, the computerized central bank observes aggregate demand in the previous round, calculates $\tilde{\pi}_{\tau}$ and sets the nominal interest, $R_{\tau}$, according to equation (7). Second, subjects are informed about the nominal interest rate and decide on consumption in the two periods of the current round. Third, the shock $\epsilon_{\tau}$ is drawn and the inflation rate $\pi_{\tau}$ for the current round is determined. And finally, after decisions were made, subjects are informed about the inflation rate, their period pay-off as well as aggregate consumption in the current round.

The assumption that the inflation rate, in contrast to the nominal interest rate, can only be observed after the consumption decision was made comes close to the timing of events in reality as well as in forward-looking models where the inflation rate relevant for savings decisions is not known with certainty ex ante. ${ }^{10}$ Although subjects are not informed about the inflation rate prior to decision making, we informed them about how inflation and interest rates were determined. Specifically, we included equations (6) and (7) in addition to verbal explanations in the instructions. Since, the shock, $\epsilon_{\tau}$, has only a relatively minor influence on the inflation rate, subjects were able, in principle, to calculate the relevant inflation rate given the observed nominal interest rate in conjunction with equation $(7) .{ }^{11}$

\footnotetext{
${ }^{10}$ To study the influence of the observability of the inflation rate in detail, we also conduct treatments in which subjects can observe the nominal interest rate as well as the inflation rate at the beginning of each round, see Section 5 .

${ }^{11}$ Note that we are not interested in the formation of expectations, which is a related but distinct issue. The
} 
To maximize total consumption in any round $\tau$, the entire endowment has to be consumed in the first period of the round if the real interest rate, $\left(1+R_{\tau}\right) /\left(1+\pi_{\tau}\right)-1$, is negative. If the real interest rate is positive, it is optimal to fully postpone consumption until the second period.

Thus, optimal first period consumption is

$$
C_{i, \tau, 1}^{*}=\left\{\begin{array}{ccc}
100 & \text { if } & R_{\tau}>\pi_{\tau} \\
0 & \text { if } & R_{\tau}<\pi_{\tau}
\end{array}\right.
$$

For $R_{\tau}=\pi_{\tau}$, optimal consumption is indeterminate.

\subsection{Calibration}

The experimental economy is parameterized as follows: we set $\bar{R}=\bar{\pi}=5$ percent, $\bar{C}=50$, and $\theta=0.03$. This calibration of $\theta$ ensures that the nominal interest rate remains strictly positive throughout all treatments. The exogenous shock to the inflation rate, $\epsilon_{\tau}$, is uniformly distributed on the interval $[-0.0005,0.0005]$. As starting values, we use $\pi_{1}=5.05$ percent and $R_{1}=5$ percent in the first round. The price in the first period is set to $P_{\tau, 1}=1$ in all rounds. The parameterization was common knowledge.

\subsection{Experimental Predictions}

To study the role of the Taylor principle, we vary $\delta$ in the interest rate rule (7) as the main treatment variable. Throughout the analysis, we consider two parameterizations of $\delta$ : In Treatment A2, we set $\delta=2$, which is a value that satisfies the Taylor principle, and in Treatment A05, we set $\delta=0.5$, which violates the Taylor principle. ${ }^{12}$ While we also implement additional treatments, which we describe below, we view Treatments A2 and A05 as our baseline treatments. Note that in both treatments, we keep the relative distance to $\delta=1$ constant.

If subjects choose consumption according to (8), the inflation rate will fluctuate around the inflation target only if the interest rate rule (7) satisfies the Taylor principle. Otherwise, if the Taylor principle is violated, inflation will persistently deviate from the target. Intuitively, suppose that average consumption in the first period of round $\tau$ is above $\bar{C}$. According to equation (6), the inflation rate will increase in round $\tau+1$. If $\delta>1$, then the nominal interest rate increases more than proportional, and, as a consequence, the real interest rate also increases. The higher real interest rate, in turn, should induce subjects to reduce consumption in the first

design of interest rate rules in environments in which the formation of expectations is more involved is studied in Pfajar and Zakelj (2011) and Assenza et al. (2011).

${ }^{12}$ Empirical studies of central bank behavior suggest(see e.g. Clarida et al., 1998) suggest that values around 2 are plausible since the early 1980s. 
period of round $\tau+1$, which leads to lower inflation in $\tau+2$. Since this mechanism also works when first-period consumption drops below $\bar{C}$, we should observe that inflation fluctuates around $\bar{\pi}$. For $\delta<1$, this stabilizing mechanism is absent. In this case, if $\frac{1}{N} \sum_{i=1}^{N} C_{i, \tau-1,1}>\bar{C}$, then inflation increases in $\tau+1$ and so does the nominal interest rate but to a lesser extent. Therefore, the real interest rate decreases, which makes it optimal to maintain a high consumption level in future rounds. Consequently, the inflation rate remains persistently above $\bar{\pi}$.

Given the parameterization described above, we should observe that the inflation rate in Treatment A2 fluctuates between 3.5 percent and 6.5 percent and should on average be equal to the inflation target. In Treatment A05, the parameterization implies that the inflation rate remains close to 6.5 percent from period 2 onwards, depending on the realizations of the shock to the inflation rate.

Note that we expect the inflation rate to fluctuate within a range of three 3 percentage points when $\delta=2$, while it should remain constant, either below or above the inflation target, when $\delta=0.5$. These predictions may seem counterintuitive at first glance as one would expect the inflation rate not only to remain close to the inflation target, if the interest rate rule obeys the Taylor principle, but also to be stable in the sense of only small fluctuations. ${ }^{13}$ These relatively large fluctuations in the stable case of our setting are a consequence of the fact that the round consumption $C_{i, \tau}$ depends linearly on $C_{i, \tau, 1}$ and $C_{i, \tau, 2}$. Therefore subjects optimally choose corner-solutions as they have no incentive to smooth consumption across periods. Consequently, the inflation rate also fluctuates relatively strongly as the computerized central bank counteracts deviations from the inflation target. We could obtain a less volatile inflation rate as the theoretical prediction in the stable case by choosing a more complex functional form for round consumption $C_{i, \tau}$. This would, however, unnecessarily complicate the set-up and might be a source of confusion in the instructions. Thus, we will analyze inflation outcomes only in terms of average deviations from the inflation target and not in terms of the volatility of the inflation rate, which would be misleading in our set-up.

\subsection{Procedure}

The experiments were implemented computerized using z-Tree (see Fischbacher, 2007) at the Ruhr-University Bochum Lab for Experimental Economics (RUBex). Participants were undergraduate students from various departments of the University of Bochum and participated only

\footnotetext{
${ }^{13}$ In fact, welfare analysis conducted using the New Keynesian model shows that inflation volatility has adverse consequences (see e.g. Galí, 2008).
} 
once in the experiment. Upon arrival, participants were randomly assigned to workstations, which were separated by blinds. Instructions were distributed and read aloud; ${ }^{14}$ participants were given a few more minutes to study the instructions and ask questions. We ran five practice rounds to acquaint the participants with the software and the structure of the experiment. These practice rounds were not payoff-relevant. The duration of one round was set to two minutes, but subjects were informed that they could go beyond this time limit if necessary (which virtually never happened).

Note that while the subjects' task is to maximize total consumption in each round, decisions made in earlier rounds may influence the payoff in later rounds to some degree, since inflation rates are linked across rounds. ${ }^{15}$ To avoid strategic super-game effects, we designed a payofffunction that induces subjects to focus on each round in isolation: in each round $\tau$, subjects

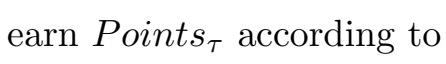

$$
\text { Points }_{\tau}=500-0.05\left(C_{\tau, 1}-C_{\tau, 1}^{*}\right)^{2}
$$

where $C_{\tau, 1}^{*}$ is consumption level in the first period that maximizes total consumption in the round. Since earnings do not depend on total round consumption, supergame-effects are eliminated. ${ }^{16}$ For the total payoff, we summed up the earned points from all 20 rounds. The conversion rate was 18.9 cents $(0.267 \$)$ per 100 points, which was common knowledge.

\section{Aggregate Inflation Dynamics}

We implemented Treatments A2 and A05 in four sessions with 10 subjects participating in each session. Each session constituted one experimental economy with $N=10$ participants.. A session lasted on average 75 minutes, and the average pay-off was 19.4 euros (max. 22.9 euros, min. 10.5 euros) including a show-up-fee of 4 euros. ${ }^{17}$

Figures 1 and 2 display the time series of the inflation rate for each of the sessions in the $\mathrm{A} 2$ and the A05 treatment. The vertical axis indicates the inflation rate and the horizontal axis shows the round. The horizontal lines indicate the inflation target.

\footnotetext{
${ }^{14}$ The instructions can be found in Appendix B.

${ }^{15}$ Suppose, for example, that the inflation rate equals the nominal interest rate in some round. In this round, any choice maximizes round consumption. However, if subjects consume everything in the first period of this round, the nominal interest rate in the next round will the higher than the inflation rate if $\delta>1$.

${ }^{16}$ Since $C_{\tau}^{*} \in\{0,100\}$ and $C_{\tau, 1} \in[0,100]$ it follows that $\left(C_{\tau, 1}-C_{\tau}^{*}\right)^{2} \leq 10000$. So if a subject makes the worst decision in round $\tau$, then Points $s_{\tau}=0$. If, in contrast, the subject makes the optimal decision, then Points $s_{\tau}=500$.

${ }^{17}$ Although pay-offs vary strongly across subjects, the average pay-off is relatively close to the maximum pay-off, which is due to the overall good performance of the participants. The payoffs converted into USD for treatments A2 and A05 were mean 27.4 USD, max. 32.35 USD, and min. 14.8 USD.
} 
(PLEASE INSERT FIGURE 1 ABOUT HERE.)

\section{(PLEASE INSERT FIGURE 2 ABOUT HERE.)}

Figure 1 shows that the inflation rates fluctuate around the target rate of 5 percent in all four sessions of Treatment A2. Recall that optimal behavior together with an interest rate that satisfies the Taylor principle implies alternating inflation rates of 3.5 and 6.5 percent and an average inflation rate equal to the inflation target of 5 percent. Although the pattern is not too clearly visible during early rounds, especially in Session 1, the oscillating pattern is generally quite pronounced and in line with the theoretical prediction. Turning to the dynamics of the inflation rate in Treatment A05, it is readily evident from Figure 2 that the inflation rate tends to persistently exceed the inflation target in each of the sessions, which is also consistent with the theoretical prediction given that the initial inflation rate is calibrated to be slightly above the inflation target.

(PLEASE INSERT TABLE 1 ABOUT HERE.)

Table 1 shows the inflation rate averaged over rounds for each session: $\left(\sum_{\tau=2}^{20} \pi_{\tau}\right) / 19$. We drop the inflation rate for the first round since it is determined exogenously. According to the table, inflation deviates on average by 0.051 percentage points from the inflation target in the four sessions of Treatment A2, and, using a Wilcoxon signed-rank test, we cannot reject the hypothesis that the inflation rate is, on average, equal to the inflation target at standard significance levels $(p=0.717)$. In Treatment A05, the average deviation from the inflation target is 0.581 percentage points, which is significantly different from zero at the ten percent significance level $(p=0.068)$ and substantially larger than in Treatment A2.

The deviations from target appear to be less systematic in Treatment A2. Here, we obtain average inflation rates above the inflation target in Sessions 1 and 4 and average inflation rates below the inflation target in Sessions 2 and 3. In Treatment A05, in contrast, the average inflation rate is above the target in each session.

We summarize these observations as our first result: 
Result 1: The computerized central bank manages to keep the average inflation rate close to the target rate if the Taylor principle is satisfied (Treatment A2). When inflationary pressure is tolerated to a greater extent (Treatment A05), inflation deviates persistently from the target.

Nevertheless, we also see that the inflation rates in Treatment A05 fall substantially short of the theoretically predicted value of 6.5 percent and we still observe some, albeit only mild, tendencies to revert back to the target in Sessions 2 and 3. Based on an a Wilcoxon signed-rank test, we can reject the hypothesis that the average inflation rate is equal to 6.5 percent at the ten percent level of significance $(p=0.068)$. So, although our results match the theoretical predictions qualitatively, deviations from the inflation target are not as pronounced as expected, when the Taylor principle is violated. Apparently subjects do not fully take the effect of inflation on the return on savings into account and base their decisions on the nominal interest rate. This outcome is consistent with at least two interpretations: First, subjects may simply not understand the influence of the inflation rate on the return to savings. That is, they may suffer from inflation illusion in a conventional sense. Alternatively, while they may understand that inflation influences the return on savings, subjects somewhat neglect its influence since it has to be inferred prior to making decisions. To see if a lack of understanding or limited information is the main reason for this behavior, we modify the environment and conduct additional treatments, which we describe in the next section, to discriminate between these two interpretations.

\section{Observability of the Inflation Rate}

To shed more light on the role of the inflation rate relative to the nominal interest rate, we implement four additional treatments, which differ from the baseline treatments discussed above along two dimensions: first, we exclude aggregation by making the inflation rate relevant for subject $i$ dependent on only the consumption decisions of subject $i$. This means we implement each treatment described in this section with individual observations $(N=1)$. The Philipps curve (6) therefore reduces to

$$
\pi_{i, \tau}=\bar{\pi}+\theta\left(C_{i, \tau-1,1}-\bar{C}\right)+\epsilon_{\tau}
$$

for subject $i$. Recall that although subjects have to infer the inflation rate in the baseline treatments, the inflation rate, apart from the shock, can in principle be calculated by using the observed nominal interest rate and the interest rate rule (7) without any additional complications arising from the aggregation of consumption choices. Nevertheless, subjects may still perceive the 
inflation rate to be harder to infer simply because inflation depends on aggregate consumption. Setting $N=1$ should eliminate any perceived influence of the other participants. ${ }^{18}$ And second, while $\delta$ remains the main treatment variable, we now also vary the degree to which the inflation rate can be observed. Comparing inflation outcomes across these treatments allows us to analyze in detail how the salience of the inflation rate influences our results.

Treatments with full information: FI2 and FI05 In treatment FI2, we set $\delta=2$, and in treatment FI05, $\delta=0.5$. In these two treatments, we make the inflation rate readily observable by presenting it on screen in the first period. Thus, if subjects understand the influence of the inflation rate on the real return, they can determine optimal consumption by comparing the displayed nominal interest rate with the displayed inflation rate. Put differently, we change the timing of events in these two treatments in the sense that the shock is drawn and also observed by the participants prior to decision making. To keep the framework and the instructions as simple as possible, we do not inform subjects that the rounds are linked through the inflation rate in these two treatments. Since the planning horizon for optimal decisions is limited to the two periods of the current round, any additional information about the underlying structure of the experimental economy is in fact redundant. ${ }^{19}$

Treatments with limited information: LI2 and LI05 In these two treatments, the inflation rate is again less salient since subjects are still informed about the nominal interest rate when they decide on consumption, but learn about the inflation rate only after the consumption decision was made as in the A2 and A05 treatments. Thus, in these two treatments, the timing of events is the same as in the baseline treatments A2 and A05. To evaluate the role of the Taylor principle, we set $\delta=2$ in Treatment LI2 and $\delta=0.5$ in Treatment LI05.

In contrast to the presentation of the results for the baseline treatment, we analyze the outcomes of the FI and LI treatments in terms of time averages of individual inflation rates. ${ }^{20}$ For each subject participating in one of the full information or limited information treatments, we calculate the average inflation rate across rounds as $\left(\sum_{\tau=2}^{19} \pi_{i, \tau}\right) / 19$, where we again drop the initial round. If subjects understand the structure of the experimental economy and use the provided information correctly, then we should observe similar outcomes as in the corresponding

\footnotetext{
${ }^{18}$ Reducing $N$ allows us to analyze a larger number of independent inflation outcomes given a certain number of subjects participating.

${ }^{19}$ Although the shock $\epsilon_{t}$ in the Phillips curve is irrelevant in Treatments FI2 and FI05, we still include it to ensure that the structure remains as similar as possible across treatments.

${ }^{20}$ See Appendix $\mathrm{C}$ for time series plots of the inflation rates for these treatments.
} 
baseline treatments A2 and A05. In total, 153 subjects participated in these treatments: 40 subjects in Treatment FI2, 34 subjects in Treatment FI05, 39 subjects in Treatment LI2, and 40 subjects in Treatment LI05. Again, sessions lasted on average 75 minutes, and the average payoff in the FI and LI treatments was 19.90 euros (max. 22.90 euros, min. 7.70 euros) including a show-up fee of 4.00 euros.

\section{(PLEASE INSERT FIGURE 3 ABOUT HERE.)}

The histograms in Figure 3 summarize the distributions of average inflation rates in the full information treatments (left Column) and in the limited information treatments (right Column). We see from the top sub-figure in the first column that the average inflation rate is between 4.5 and 5.5 percent for roughly 90 percent of the subjects who participated in the FI2 Treatment. Thus, for the vast majority of subjects in this treatment, the computerized central bank manages to keep average inflation close to the target of 5 percent, as predicted.

Given our calibration, we should observe average inflation rates of around 6.5 percent in Treatment FI05. The second sub-figure in the first column of Figure 3 shows that the distribution of average inflation rates in Treatment FI05 is indeed strongly skewed. For slightly more than 50 percent of the subjects, the average inflation rate is between 6 percent and 7 percent.

In this treatment, we also observe relatively low average inflation rates. This is partly due to the fact that several subjects make mistakes in early rounds and choose low consumption levels despite a negative real interest rate. Subsequently, low consumption in the first period is reinforced, since the real interest rate becomes positive as consumption is now below $\bar{C}=50$. Consequently, the optimal choice for first-period consumption in the remaining rounds becomes $C_{\tau, 1}^{*}=0$. Hence, while our calibration implies that the average inflation rate should be around 6.5 percent in Treatment FI05, early mistakes and optimal behavior afterwards should indeed lead to an average inflation rate of around 3.5 percent.

In any case, average inflation rates are either above or below the inflation target for the majority of subjects in Treatment FI05. In fact, the computerized central bank manages to keep the average inflation rate close to the inflation target of 5 percent for less than 10 percent of the subjects when $\delta=0.5$. Hence, when the inflation rate is displayed on screen, obeying the Taylor principle is not only sufficient for hitting the inflation target on average, but also appears to be a necessary requirement as expected. 
Do the results change when the inflation rate is less salient? If it is indeed primarily the salience of the inflation rate that matters, then the violation of the Taylor principle in Treatment LI05 should lead to no or only small deviations from the inflation target on average and we should observe similar inflation outcomes in the LI2 and LI05 treatments.

The second column of Figure 3 shows histograms of the average inflation rates in the LI2 (top) and LI05 (bottom) treatments. For the LI2 treatment, we still observe a qualitatively similar picture as in the corresponding full information treatment. The distribution is centered around the inflation target, and for around 80 percent of the subjects, the average inflation rate is between 4.5 percent and 5.5 percent. Nevertheless, deviations are now somewhat more pronounced and the range of observed average inflation rates is now a bit wider, which is not unexpected given the somewhat more involved task in this treatment. The bottom sub-figure in the second column shows that we obtain average inflation rates between 4.5 percent and 5.5 percent for almost 50 percent of the subjects in Treatment LI05. Thus, the distribution of average inflation rates in Treatment LI05 is also centered around the inflation target, although the interest rate rule violates the Taylor principle.

\section{(PLEASE INSERT TABLE 2 ABOUT HERE.)}

Table 2 shows the average inflation rates in the full and limited information treatments and reports the $p$-values based on the Wilcoxon signed-ranks test for comparisons between observed inflation rates and the inflation target, and for Mann-Whitney rank sum tests for comparing inflation outcomes across treatments. ${ }^{21}$ We summarize the main results as follows:

Result 2: If the interest rate rule satisfies the Taylor principle, then the average inflation rate is close to the inflation target regardless of information available to subjects.

Support for Result 2: The average inflation rates are 5.127 percent and 5.067 percent in Treatments FI2 and LI2, respectively and we cannot reject the null hypothesis that the observed inflation rates in the FI2 and LI2 treatments are from populations characterized by the same distribution $(p=0.556)$. Although the deviation from the target is insignificant in Treatment LI2 $(p=0.171)$, it is significantly different from zero at the one percent level $(p=0.002)$, albeit still small in an economic sense, in Treatment FI2.

\footnotetext{
${ }^{21}$ Note that we perform the test with inflation rates averaged across rounds since the individual observations are serially correlated by construction. Consequently, we reduce the sample to one observation per subject, and therefore, we use non-parametric tests to take the small sample size into account. In addition, we conducted standard $t$-tests, which yield qualitatively identical results.
} 
Result 3: If the inflation rate can be readily observed, deviations from the inflation target are on average more pronounced when the interest rate rule violates the Taylor principle.

Support for Result 3: The average inflation rate of 5.583 percent in Treatment FI05, is substantially higher than in Treatment FI2 (5.127 percent), ${ }^{22}$ and the hypothesis that the observed inflation rates in these two treatments are from the same distribution can be rejected at the one percent level $(p=0.001){ }^{23}$

Result 4: When the inflation rate is less salient, the average inflation rate is close to the inflation target even when the interest rate rule violates the Taylor principle.

Support for Result 4: The average inflation rate of 4.957 percent in Treatment LI05, is not significantly different from the inflation target $(p=0.657)$ nor from the average inflation rate in the corresponding treatment with full information $(p=0.290)$, which is 5.067 percent.

Overall, these results confirm our previously reported findings suggesting that as long as the interest rate rule satisfies the Taylor principle, average inflation rates are close to the inflation target, regardless of the amount of information available to subjects. We also see that as long as subjects are fully aware of the inflation rate, an interest rate rule that does not satisfy the Taylor principle leads to systematic deviations from the inflation target, which is in line with theoretical predictions.

Thus, we conclude that subjects understand how inflation influences the return on savings. Hence, we find no evidence for inflation illusion in the sense that subjects are either not aware of the consequences of inflation nor that they simply ignore the inflation rate. Nevertheless, we also see that a less salient inflation rate leads to rather different outcomes. If the inflation rate cannot be easily observed, subjects tend to pay less attention and equate the nominal return with the real return.

\section{Additional Analysis}

To better understand the subjects' choices in the experiment, we evaluate answers provided in a debriefing questionnaire. Since Smith (2003), amongst others, questions the validity of such selfreported descriptions of behavior, we restrict our analysis to the depicted components and a clear

\footnotetext{
${ }^{22}$ Recall that in the treatments with $\delta=0.5$ we expect that inflation rates exceed the target since we set the initial inflation rate above the target.

${ }^{23}$ Note that we can also reject the null hypothesis that $\pi$ is equal to the predicted value of 6.5 in Treatment FI05 at the one percent level $(p<0.000)$.
} 
description of the correct behavior. We find that 22 percent of the subjects who participated in the limited information treatments state that they relied only on the nominal interest rate when making decisions, while this is true for less than 3 percent in the full information treatments. Hence, the nominal interest rate indeed plays a more relevant role when the inflation rate is less salient. Moreover, in the treatments with full information, 52 percent of the subjects describe their behavior as being based on the real interest rate, and for 35 percent, the description of their behavior corresponds to the optimal decision rule. In contrast, in the treatments with limited information, where the inflation rate is less salient, only 16 percent of the subjects state that they took the real interest rate into account and only 6 percent stated to have used the correct decision rule. ${ }^{24}$

In short, the nominal interest rate gains importance and the real interest rate turns out to be less relevant when the inflation rate becomes less salient. These additional results support our conclusion that it is mainly the less salient inflation rate that can explain deviations from the Fisher equation in some of our treatments.

Although we designed the experiment in a way that isolates the effects of the nominal interest rate and the inflation rate, it still remains conceivable that subjects behave in a different way. It is well known that repetitive tasks in experimental settings and the associated boredom may give rise to behavior that is hard to interpret (Smith, 1976; Siegel, 1961). One conceivable scenario would be random choice behavior due to the humdrum assignment of repeatedly entering the same value(s). However, this type of behavior seems unlikely in our setting for at least two reasons. First, boredom-related behavior would emerge or increase over the course of the experiment, while we observe a rather stable pattern. And second, using a Kolmogorv-Smirnov test, we are able to reject the null hypothesis that the observed consumption choices are simply drawn from a random distribution between 0 and 100 at least at the 5 percent level for all treatments.

Since our setting has the interesting feature that optimal solutions are corner-solutions in the sense that it is optimal to either consume the entire endowment in the first period or nothing, we report the frequencies of chosen corner-solutions in Table 3. For each treatment, the table shows the fractions of subjects who chose the correct corner-solution to obtain the maximum payoff for the round, and the fractions of subjects who also chose a corner-solutions, but the incorrect one, leading to payoff of zero in this round. The last column of the table shows the

\footnotetext{
${ }^{24}$ In the baseline treatments with aggregation, 28 percent of subjects emphasize the nominal interest rate, 20 percent report that they focused on the real interest rate, and 12 percent provide a description of their behavior that matches the optimal decision rule.
} 
averages across rounds for each treatment.

\section{(PLEASE INSERT TABLE 3 ABOUT HERE.)}

The table shows that the fractions of correctly chosen corner-solutions increase over rounds in all treatments, which indicates that subjects were more willing to choose the corner solution, as they became more familiar with the environment. The fraction of correctly chosen corner-solutions is higher in the treatment with full information which is consistent with the interpretation that the task is less demanding in this treatment. ${ }^{25}$ While a few subjects chose the incorrect corner solution, resulting in a payoff of zero, this outcome occurs relatively rarely even in the limited information treatments.

\section{Conclusion}

In this paper, we propose an experimental approach to evaluate the stability properties associated with interest rate rules. In theory, monetary policy can stabilize the economy by responding to inflationary pressure in accordance with the Taylor principle.

In line with this view, we find in essentially all the treatments we analyze that the average inflation rate is close to the inflation target when the computerized central bank sets interest rates in line with the Taylor principle. However, we also find that even if the interest rate rule violates the Taylor principle, deviations from the target are less pronounced than predicted by the theory if the inflation rate has to be inferred. These results are consistent with the interpretation that subjects display some mild inflation illusion and overemphasize the nominal interest rate relative to the inflation rate if the inflation rate cannot be as readily observed as the nominal interest rate. While the direct effect of inflation illusion is small, since subjects understand the influence of inflation and take these properly into account, a less salient inflation rate strongly amplifies the effect. In this sense, our result shares some similarities with Fehr and Tyran (2001) who show that money illusion per se has only small implications, while becoming more relevant when coordination issues are introduced. We show - in a different setting without coordination issues - that limited information acts in a similar way.

\section{Acknowledgments}

\section{T.B.A}

\footnotetext{
${ }^{25}$ We can reject the null hypothesis that the fractions of correctly chosen corner-solutions are equal in the full information and limited information treatments at the one percent level, for $\delta=0.5(p<0.000)$ and for $\delta=2$ $(p<0.000)$.
} 


\section{References}

Ahmed, S., Levin, A., Wilson, B. A., 2004. Recent U.S. macroeconomic stability: Good policies, good practices, or good luck? The Review of Economics and Statistics 86 (3), 824-832.

Arifovic, J., Bullard, J., Kostyshyna, O., 03 2013. Social learning and monetary policy rules. Economic Journal 123 (567), 38-76.

Assenza, T., Heemeijer, P., Hommes, C., Massaro, D., May 2011. Individual expectations and aggregate macro behavior. DNB Working Papers 298, Netherlands Central Bank, Research Department.

Ballinger, T., Palumbo, M., Wilcox, N., 2003. Precautionary saving and social learning across generations: An experiment. The Economic Journal 113 (490), 920-947.

Bao, T., Duffy, J., Hommes, C., 2013. Learning, forecasting and optimizing: An experimental study. European Economic Review 61, 186-204.

Blanchard, O., Simon, J., 2001. The long and large decline in U.S. output volatility. Brookings Papers on Economic Activity 32 (2001-1), 135-174.

Brunnermeier, M. K., Julliard, C., January 2008. Money illusion and housing frenzies. Review of Financial Studies 21 (1), 135-180.

Bullard, J., Mitra, K., 2002. Learning about monetary policy rules. Journal of Monetary Economics 49 (6), 1105-1129.

Campbell, J. Y., Vuolteenaho, T., 2004. Inflation illusion and stock prices. American Economic Review 94 (2), 19-23.

Carbone, E., Hey, J., 2004. The effect of unemployment on consumption: An experimental analysis. The Economic Journal 114 (497), 660-683.

Carlstrom, C. T., Fuerst, T. S., 2005. Investment and interest rate policy: a discrete time analysis. Journal of Economic Theory 123 (1), 4-20.

Clarida, R., Galí, J., Gertler, M., 1999. The science of monetary policy: A New Keynesian perspective. Journal of Economic Literature 37 (4), 1661-1707.

Clarida, R. H., Galí, J., Gertler, M., 1998. Monetary policy rules in practice: Some international evidence. European Economic Review 42 (6), 1033-1067. 
Clarida, R. H., Galí, J., Gertler, M., 2000. Monetary policy rules and macroeconomic stability: Evidence and some theory. Quarterly Journal of Economics 115 (1), 147-180.

Davig, T., Leeper, E. M., June 2007. Generalizing the taylor principle. American Economic Review 97 (3), 607-635.

Davis, S. J., Kahn, J. A., 2008. Interpreting the great moderation: Changes in the volatility of economic activity at the macro and micro levels. NBER Working Papers 14048, National Bureau of Economic Research, Inc.

De Fiore, F., Liu, Z., 2005. Does trade openness matter for aggregate instability? Journal of Economic Dynamics and Control 27 (7), 1165-1192.

Duffy, J., Xiao, W., 2011. Investment and monetary policy: Learning and determinacy of equilibrium. Journal of Money, Credit and Banking 43 (5), 959-992.

Dynan, K. E., Elmendorf, D. W., Sichel, D. E., January 2006. Can financial innovation help to explain the reduced volatility of economic activity? Journal of Monetary Economics 53 (1), $123-150$.

Ehrmann, M., Tzamourani, P., 2012. Memories of high inflation. European Journal of Political Economy 28, 174-191.

Engle-Warnick, J. E., Turdaliev, N., 2010. An experimental test of Taylor-type rules with inexperienced central bankers. Experimental Economics 13 (2), 146-166.

Fair, R. C., 2005. Estimates of the effectiveness of monetary policy. Journal of Money, Credit and Banking 37 (4), 645-60.

Fehr, E., Tyran, J., 2001. Does money illusion matter? American Economic Review 91 (5), $1239-62$.

Fischbacher, U., 2007. z-tree: Zurich toolbox for ready-made economic experiments. Experimental Economics 10 (2), 171-178.

Fisher, I., 1928. The Money Illusion. Adelphi Company, New York.

Galí, J., 2008. Monetary Policy, Inflation, and the Business Cycle: An Introduction to the New Keynesian Framework. Princeton University Press, Princeton, New Jersey. 
Galí, J., Lòpez-Salido, D. J., Vallés, J., 2004. Rule-of-thumb consumers and the design of interest rate rules. Journal of Money, Credit and Banking 36 (4), 739-764.

Hey, J., Dardanoni, V., 1988. Optimal consumption under uncertainty: An experimental investigation. Economic Journal 98 (390), 105-16.

Judd, J. F., Rudebush, G. D., 1998. Taylor's rules and the Fed. Federal Reserve Bank of San Francisco Economic Review, 3-16.

Lei, V., Noussair, C., 2002. An experimental test of an optimal growth model. American Economic Review 92 (3), 411-433.

Modigliani, F., Cohn, R., 1979. Inflation, rational valuation and the market. Financial Analyst Journal 37 (3), 24-44.

Noussair, C., Matheny, K., 2000. An experimental study of decisions in dynamic optimization problems. Economic Theory 15 (2), 389-419.

Noussair, C. N., Pfajar, D., Zsiros, J., August 2011. Frictions, persistence, and central bank policy in an experimental dynamic stochastic general equilibrium economy, mimeo.

Orland, A., Roos, M. W., 2013. The new keynesian phillips curve with myopic agents. Journal of Economic Dynamics and Control 37 (11), 2270-2286.

Orphanides, A., 2004. Monetary policy rules, macroeconomic stability and inflation: A view from the trenches. Journal of Money, Credit, and Banking 36 (2), 151-175.

Petersen, L., Winn, A., 2014. Does money illusion matter?: Comment. The American Economic Review 104 (3), 1047-1062.

Peterson, L., Krystov, O., 2013. Expectations and monetary policy: Experimental evidence expectations and monetary policy: Experimental evidence.

Peterson, L. a., 2012. Non-neutrality of money, preferences and expectations in laboratory New Keynesian economics. Working Paper 8, Sury Initiative for Global Finance and International Risk Management (SIGFIRM) at the University of California.

Pfajar, D., Zakelj, B., July 2011. Inflation expectations and monetary policy design: Evidence from the laboratory, mimeo. 
Piazzesi, M., Schneider, M., 2008. Inflation illusion, credit, and asset prices. In: Asset prices and monetary policy. University of Chicago Press, pp. 147-189.

Shiller, R. J., 1997. Why do people dislike inflation? In: Romer, C., Romer, D. (Eds.), Reducing Inflation: Motivation and Strategy. National Bureau of Economic Research, Inc, pp. 13-70.

Siegel, S., 1961. Decision making and learning under varying conditions of reinforcement. Annals of the New York Academy of Sciences 89 (5), 766-783.

Smith, V., 1976. Experimental economics: Induced value theory. The American Economic Review 66 (2), 274-279.

Smith, V., 2003. Constructivist and ecological rationality in economics. The American Economic Review 93 (3), 465-508.

Stock, J. H., Watson, M. W., 2005. Understanding changes in international business cycle dynamics. Journal of the European Economic Association 3 (5), 968-1006.

Sveen, T., Weinke, L., 2007. Firm-specific capital, nominal rigidities, and the taylor principle. Journal of Economic Theory 136 (1), 729-737.

Taylor, J. B., 1999. A historical analysis of monetary policy rules. In: Taylor, J. B. (Ed.), Monetary Policy Rules. University of Chicago Press, Chicago, pp. 1305-1311.

Tyran, J., 2007. Money Illusion and the Market. Science 317 (5841), 1042-1043.

Woodford, M., 2003. Interest and Prices: Foundations of a Theory of Monetary Policy. Princeton University Press, Princeton, New Jersey. 


\section{A Inflation Illusion and the Taylor Principle}

Consider equations (4) and (5) together with the interest rate rule (3). To see how inflation illusion may influence the determinacy properties of the New Keynesian model we modify equation (4) in the sense that the expected inflation rate enters with a coefficient $\gamma>0$ :

$$
Y_{t}=-a\left(R_{t}-\gamma E_{t} \pi_{t+1}\right)+E_{t} Y_{t+1}
$$

This parameter indexes the strength of inflation illusion: For $\gamma<1$ we obtain inflation illusion in the sense that expected inflation is not fully taken into account. $\gamma=1$ is the standard case, and $\gamma>1$ corresponds to an excessive influence of expected inflation.

Using equations equations (3) and (5), the modified Euler equation (A.1) can be written as:

$$
Y_{t}=\frac{a \gamma-a \delta c}{1+a d \delta} E_{t} \pi_{t+1}+\frac{1}{1+a d \delta} E_{t} Y_{t+1}
$$

Let $z_{t}=\left(\pi_{t}, Y_{t}\right) \prime$, then the system (5) and (A.1) can be written as

$$
A_{0} E_{t} z_{t+1}=A_{1} z_{t}
$$

where

$$
A_{0}=\left(\begin{array}{cc}
c & 0 \\
\frac{a \gamma-a \delta c}{1+a d \delta} & \frac{1}{1+a d \delta}
\end{array}\right)
$$

and

$$
A_{1}=\left(\begin{array}{cc}
1 & -d \\
0 & 1
\end{array}\right)
$$

Rearranging gives

$$
E_{t} z_{t+1}=A z_{t},
$$

where

$$
A=A_{0}^{-1} A_{1}=\left(\begin{array}{cc}
\frac{1}{c} & -\frac{d}{c} \\
\frac{a(\delta c-\gamma)}{c} & \frac{a d \gamma+c}{c}
\end{array}\right) .
$$

Since $y_{t}$ and $\pi_{t}$ are both non-predetermined variables, the rational expectations equilibrium of the model is determinate if and only if the matrix $A$ has both eigenvalues outside the unit circle. As shown in Woodford (2003), ${ }^{26}$ this condition is satisfied if

$$
\begin{gathered}
\operatorname{det}(A)>0, \\
1+\operatorname{det}(A)+\operatorname{tr}(A)>0,
\end{gathered}
$$

\footnotetext{
${ }^{26}$ See Appendix C.
} 
and

$$
1+\operatorname{det}(A)-\operatorname{tr}(A)>0 \text {. }
$$

Since $\operatorname{det}(A)=(1+a d \delta) / c>0$ and $\operatorname{tr}(A)=(1+c+a d \gamma) / c>0$, conditions (A.8) and (A.9) are satisfied and condition (A.10) can be written as

$$
\frac{a d(\delta-\gamma)}{c}>0
$$

Hence, the equilibrium is determinate if and only if $\delta>\gamma$. Note that for the standard model with $\gamma=1$, this condition is simply the standard Taylor principle. In the case of inflation illusion $(\gamma<1)$, values of $\delta$ below unity may be consistent with a determinate equilibrium. And for $\gamma>1$, the standard Taylor principle is no longer sufficient for determinacy. 


\section{B Instructions for Treatment A2}

Welcome to the experiment. Please do not talk to any other participant from now on. We kindly ask you to use only those functions of the PC that are necessary for the conduct of the experiment.

The purpose of the experiment is to study decision behavior. You can earn real money in this experiment. Your payment will be determined solely by your own decisions according to the rules on the following pages.

The data from the experiment will be anonymized and cannot be related to the identities of the participants. Neither the other participants nor the experimenter will find out which choices you have made and how much you have earned during the experiment.

\section{Groups}

At the beginning of the experiment you will be randomly assigned to one of two groups consisting of 10 persons each. During the experiment, your group, either 1 or 2, will be displayed at the upper margin of the screen. The group you are assigned to has no impact on the task or the payoff.

\section{Task}

In this experiment you have to make decisions concerning consumption and saving. Your task is to decide on the allocation of a virtual wealth of 100 Taler between two periods in order to maximize your aggregate consumption over both periods. Thus, your goal is to choose consumption in period 1 to maximize consumption in periods 1 AND 2.

\section{Period 1 consumption}

In period 1 you are endowed with 100 Taler. You have to decide how many goods to buy in this period. The price of the good in period 1 is $P_{1}$. If you want to consume a quantity $C_{1}$ in period 1, you will have to spend $C_{1} \times P_{1}$ Taler. The time limit for your decision is 2 minutes. The remaining time is displayed (in seconds) at the top part of the screen.

\section{Saving and period 2 consumption}

After you have decided on consumption in period 1, the remaining endowment will be saved automatically yielding a return of $i \%$.

The remaining endowment and the interest income constitute your disposable income in 
period 2:

$$
\text { Disposable Income in per. } 2=(1+i \%) \times \text { remaining endowment }
$$

Your entire disposable income will be used to buy goods at the price effective in period $2, P_{2}$. Hence, your consumption in period 2 is:

$$
C_{2}=\frac{\text { remaining endowment } \times(1+i \%)}{P_{2}}
$$

Your consumption choice in period 1 will therefore also determine your consumption in period 2 , depending on prices and the interest rate.

\section{Rounds}

We refer to two periods involving your consumption decisions as one round. The experiment consists of 20 rounds. As soon as you have decided on the consumption in period 1 (and hence also in period 2) the round is over. You will receive information about your consumption in each period and on your aggregate consumption in this round.

Subsequently the next round will start. You will again be endowed with 100 Taler and have to decide on the consumption in period 1 .

Neither Taler nor goods can be transferred between rounds. Note that prices and the interest rate may change from period to period.

\section{Display and entries}

At the beginning of each round, before you make your decision, the price $P_{1}$ and the interest rate $i$ will be displayed. You will not be informed about the price change between the periods or the price in period $2\left(P_{2}\right)$ until the end of the round.

In this experiment all numbers have three decimal places. You can enter your consumption choice up to the third decimal place - but this is not obligatory.

Should you require a calculator, you can either use your own or click on the calculator symbol at the lower margin of the screen to open the Windows calculator.

\section{Price change within one round}

The price in every round's first period is equal to one: $P_{1}=1$. The price in the second period, $P_{2}$, may deviate from one. The price change from the first to the second period of one round depends on the average consumption of your group in the previous round. More precisely, 
the price change depends on the average consumption in the first period of the previous round. The price change is determined as follows:

$$
\text { Price change }(\text { in } \%)=5 \%+0.03 \times\left(\bar{C}_{1} \text { in the last round }-50\right)+u \text {, }
$$

where $\bar{C}_{1}$ is the average consumption of all participants in your group.

On average, the price increases by $5 \%$ between period 1 and period 2 . If average consumption in the previous round has exceeded 50 units, the price will increase by more than $5 \%$ in the current round. If the average consumption was less than 50 units the price increase will be smaller.

The price change does not only depend on the consumption in the previous round but contains an additional random component. This component is denoted by $u$ in the equation above and can be any arbitrary number between $-0.05 \%$ and $+0.05 \%$. Each value in this interval has the same probability.

\section{Interest rate}

The interest rate is set by the Experimental Central Bank (ECB) depending on the price change in the current round. The ECB cannot, however, observe the random component $u$ and will therefore use the expected price change, that is, the price change that would result if $u$ were equal to zero, as a basis for interest rate setting:

$$
i=5 \%+2 \times(\text { expected price change in } \%-5 \%) \text {. }
$$

If the ECB expects the price change to be above $5 \%$ the interest rate will also rise above $5 \%$. If the expected price change is smaller than $5 \%$ the interest rate will fall below $5 \%$.

Note that the change in the interest rate will always exceed the price change.

\section{Example}

Assume the interest rate is $5 \%$ and the price of the good is 1 Taler in period 1 and 1.1 Taler in period 2 .

If you consume e.g. 83 units in the first period, you automatically spend $17 \times(1+0.05)=17.85$

Taler for goods in period 2. Given the price of 1.1 Taler in period 2 you would consume $17.85 / 1.1=16.23$ units of the consumption good in the second period, yielding a total consumption of $83+16.23=99.23$ goods in this round. 


\section{Payoff}

You receive an upfront payment of 4.00 euro for attending this session. Your total payoff in euros depends on the total amount of goods consumed in both periods of one round. The higher your total round consumption, the more you earn at the end of the experiment.

Your payoff is calculated as follows: For every round, there is one specific value of consumption in period 1 that will maximize your total consumption in both periods. This optimal value of one round depends on the prices and the interest rate in this round.

The closer your chosen consumption comes to the optimal value, the more "points" you earn in the round. Points are calculated as

$$
\text { Points }=500-0.05\left(C_{1}-C_{1}^{*}\right)^{2}
$$

where $C_{1}$ is the consumption you chose in the first period of this round and $C_{1}^{*}$ is the optimal value. You can earn between 0 and 500 points in each round. One point is worth 0.0019 euro and 100 points are worth 19 cents. 526 points therefore correspond to 1 euro. For the total payoff, all rounds' earnings are added and converted into euros.

\section{Trial}

Before the experiment starts there will be a trial run consisting of 5 rounds. The results from the trial do not affect your final payoffs.

\section{End}

After completing a short questionnaire you will be paid privately. Please bring the receipt and the card indicating your workstation number with you. 
C Inflation Rates in the FI and LI Treatments

(PLEASE INSERT FIGURE C.1 ABOUT HERE.)

(PLEASE INSERT FIGURE C.2 ABOUT HERE.)

(PLEASE INSERT FIGURE C.3 ABOUT HERE.)

(PLEASE INSERT FIGURE C.4 ABOUT HERE.) 
Table 1: Average Inflation Rates in the Baseline Treatments

\begin{tabular}{cll}
\hline \hline & \multicolumn{2}{c}{ Treatment } \\
Session & A2 & A05 \\
\hline 1 & 5.402 & 5.789 \\
2 & 4.800 & 5.410 \\
3 & 4.985 & 5.400 \\
4 & 5.017 & 5.726 \\
\hline Average & 5.051 & 5.581 \\
\hline \hline
\end{tabular}

Notes: The table shows average inflation rates in each session of the A2 $(\delta=2)$ and A05 $(\delta=0.5)$ Treatments. The averages are taken over rounds, and the first round is dropped since the initial inflation rate is determined exogenously. The last line reports the overall averages taken over time and over the sessions in each treatment. 


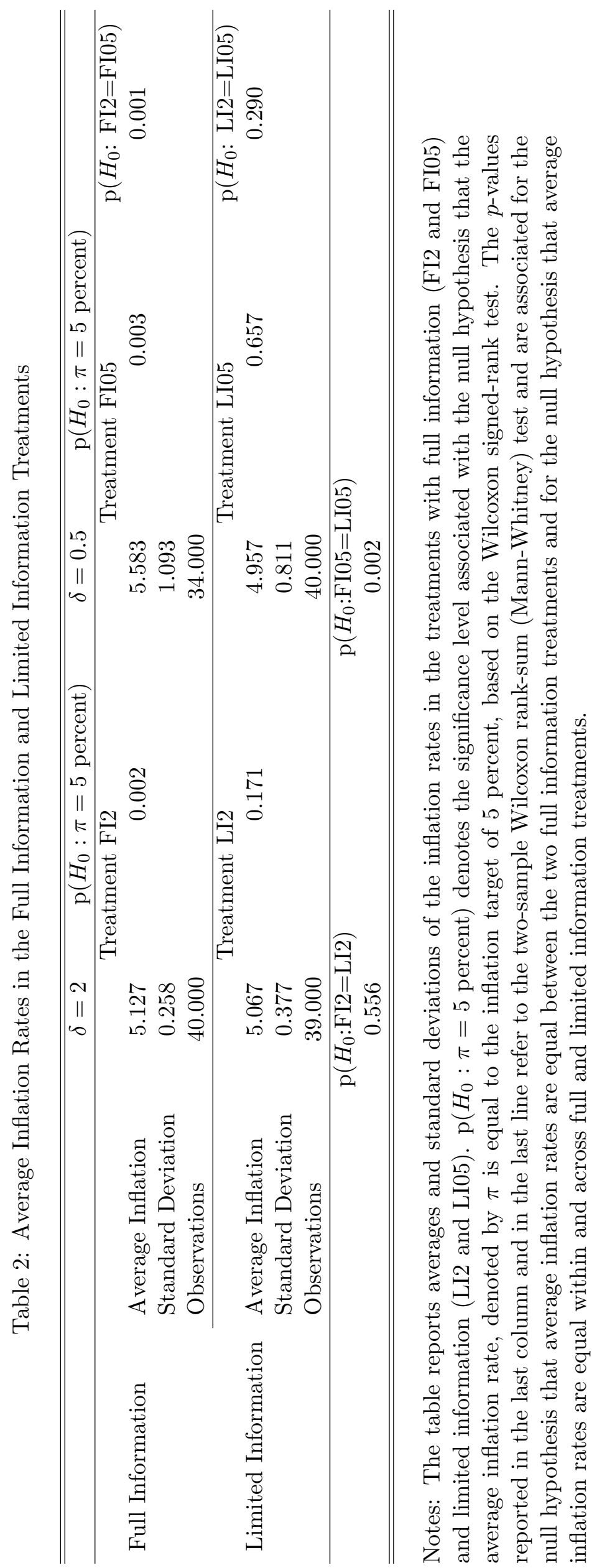


Figure 1: Inflation Rates in the A2 Treatment
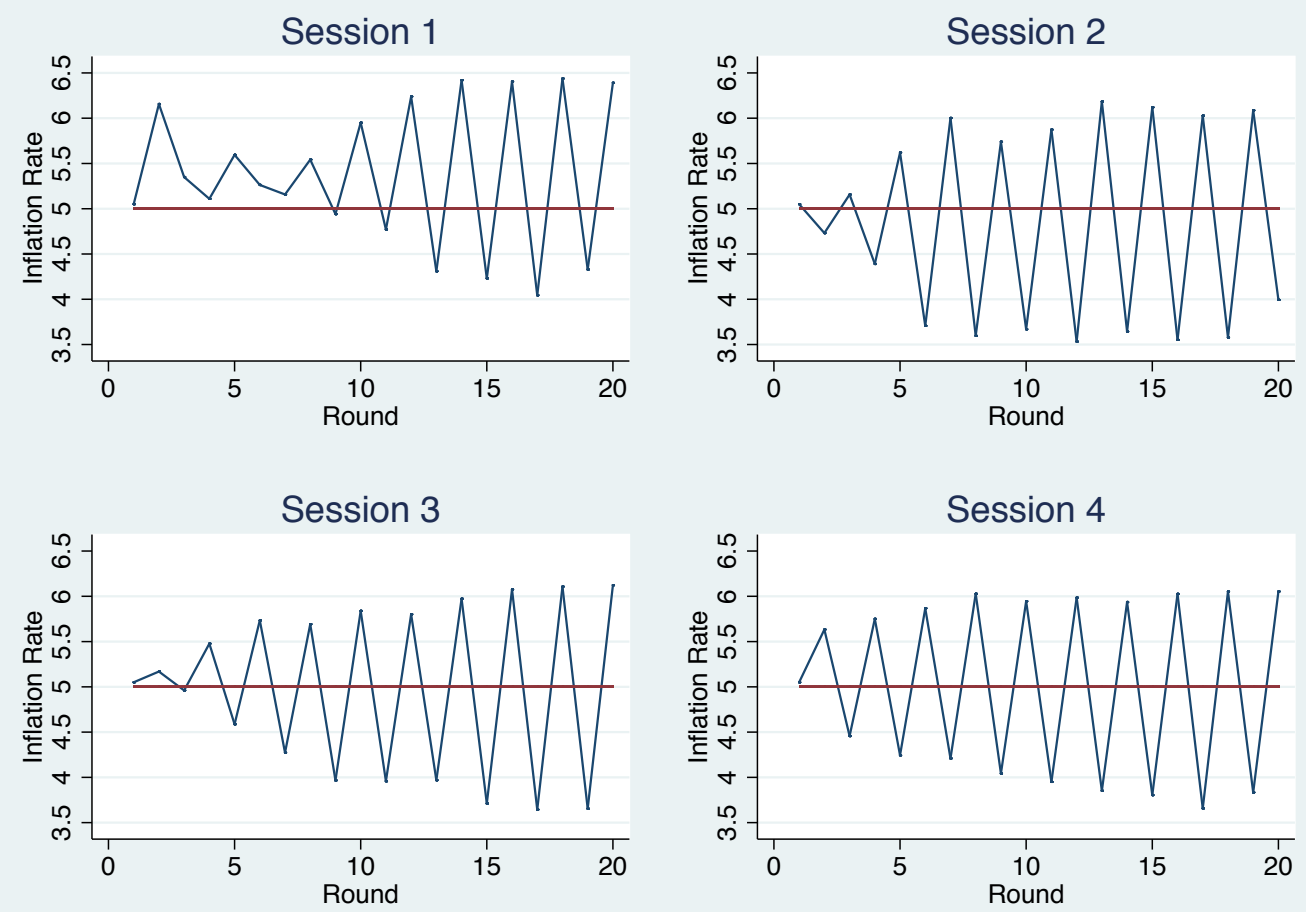

Notes: The four sub-figures show inflation rates in the four sessions of the A2 Treatment. The horizontal lines indicate the inflation target of 5 percent. 
Figure 2: Inflation Rates in the A05 Treatment
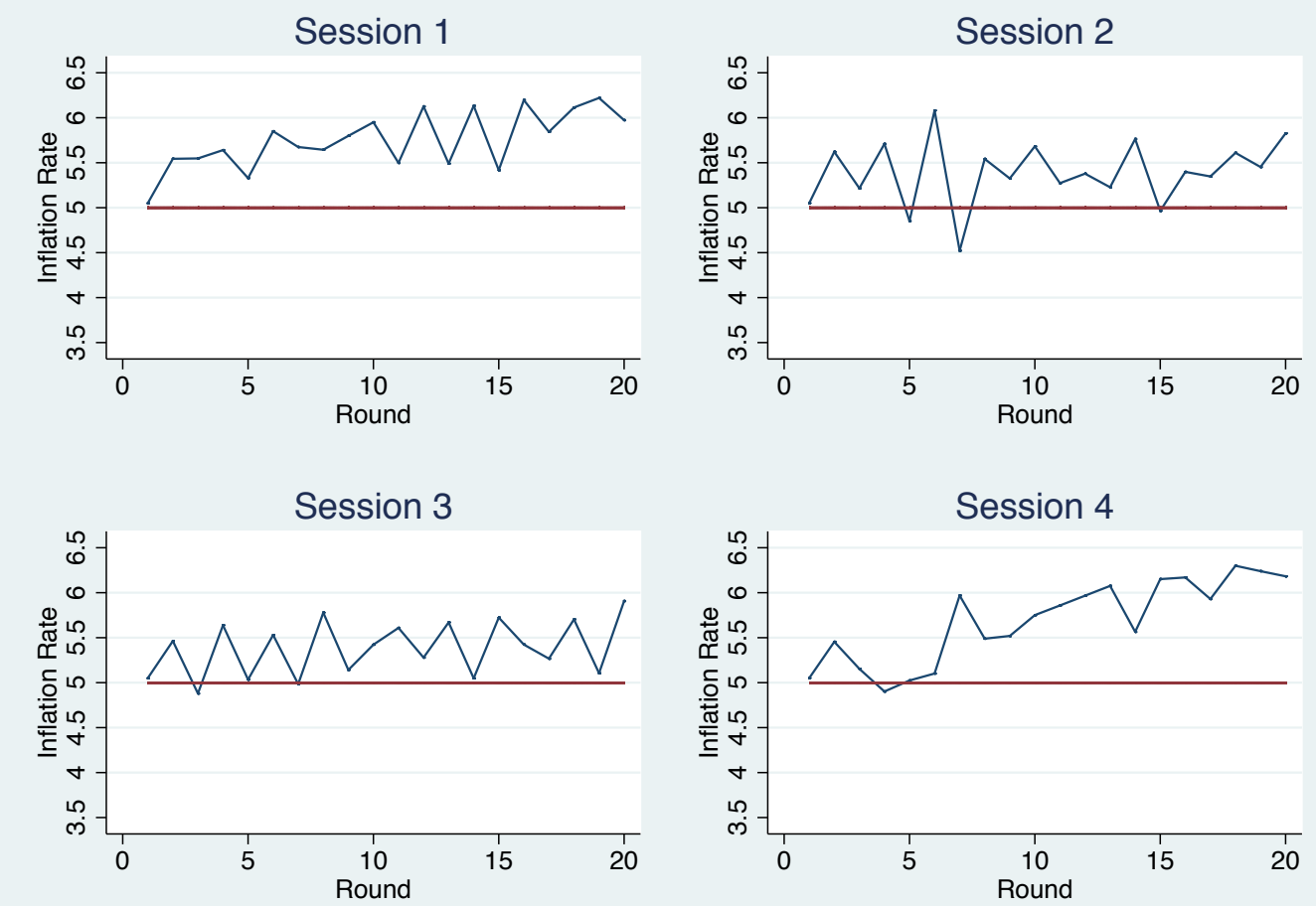

Notes: The four sub-figures show inflation rates in the four sessions of the A05 Treatment. The horizontal lines indicate the inflation target of 5 percent 
Figure 3: Distribution of Average Inflation Rates in the FI and LI Treatments

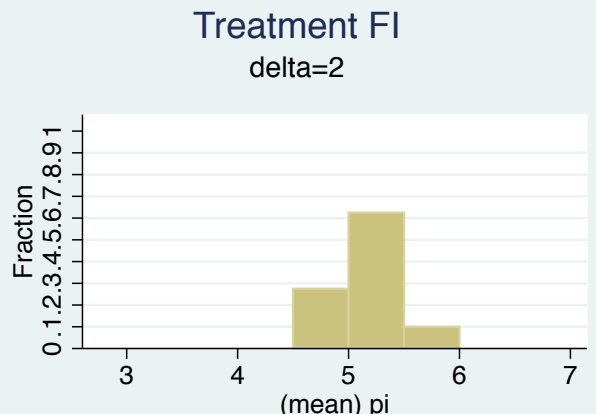

delta $=1 / 2$

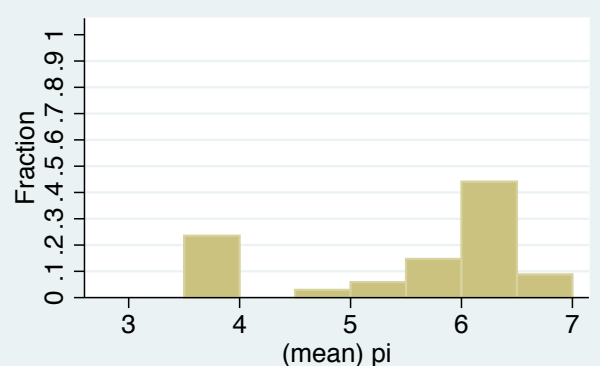

Treatment LI

delta $=2$

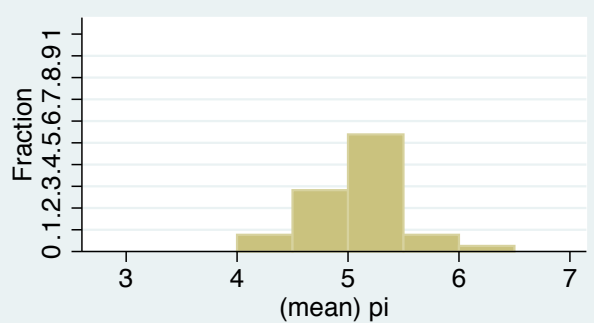

delta $=1 / 2$

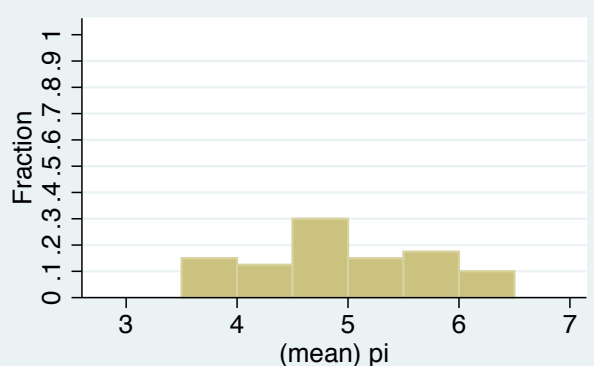

Notes: The sub-figures show histograms for average, individual inflation rates in the FI (left Column) and LI (right Column) treatments. The average inflation rate across rounds is calculated as $\pi_{i}=\frac{1}{19} \sum_{\tau=2}^{20} \pi_{i, \tau}$ for each subject $i$. 
Figure C.1: Inflation Rates in Treatment FI2

\begin{tabular}{|c|c|c|}
\hline 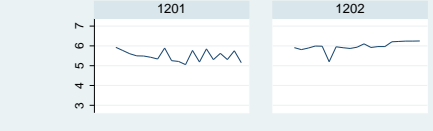 & WWWEN WMWE & 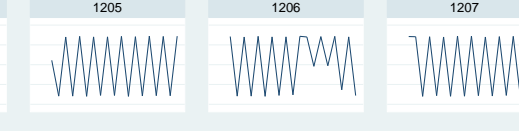 \\
\hline DWW & Whaw Wha & 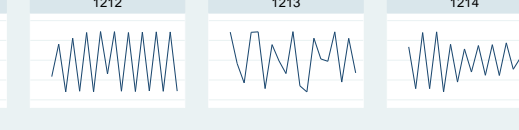 \\
\hline 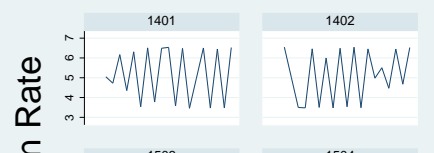 & w'm & WWWW WWWW WWW \\
\hline 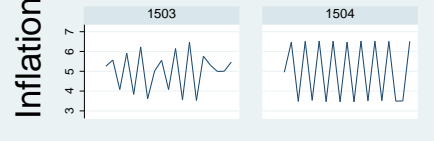 & awy whe & 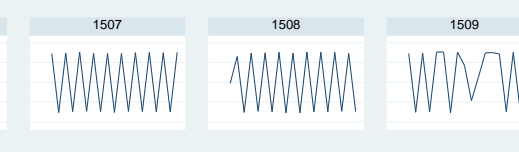 \\
\hline InWWM & 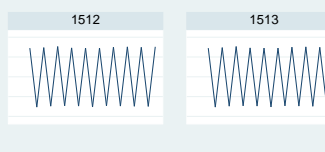 & 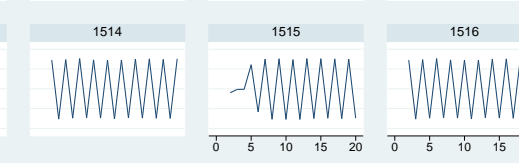 \\
\hline 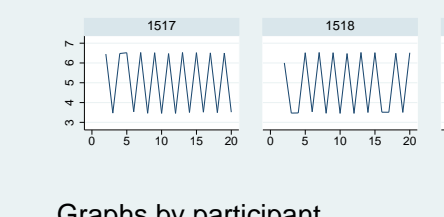 & Rim & Mwer \\
\hline
\end{tabular}


Figure C.2: Inflation Rates in Treatment FI05

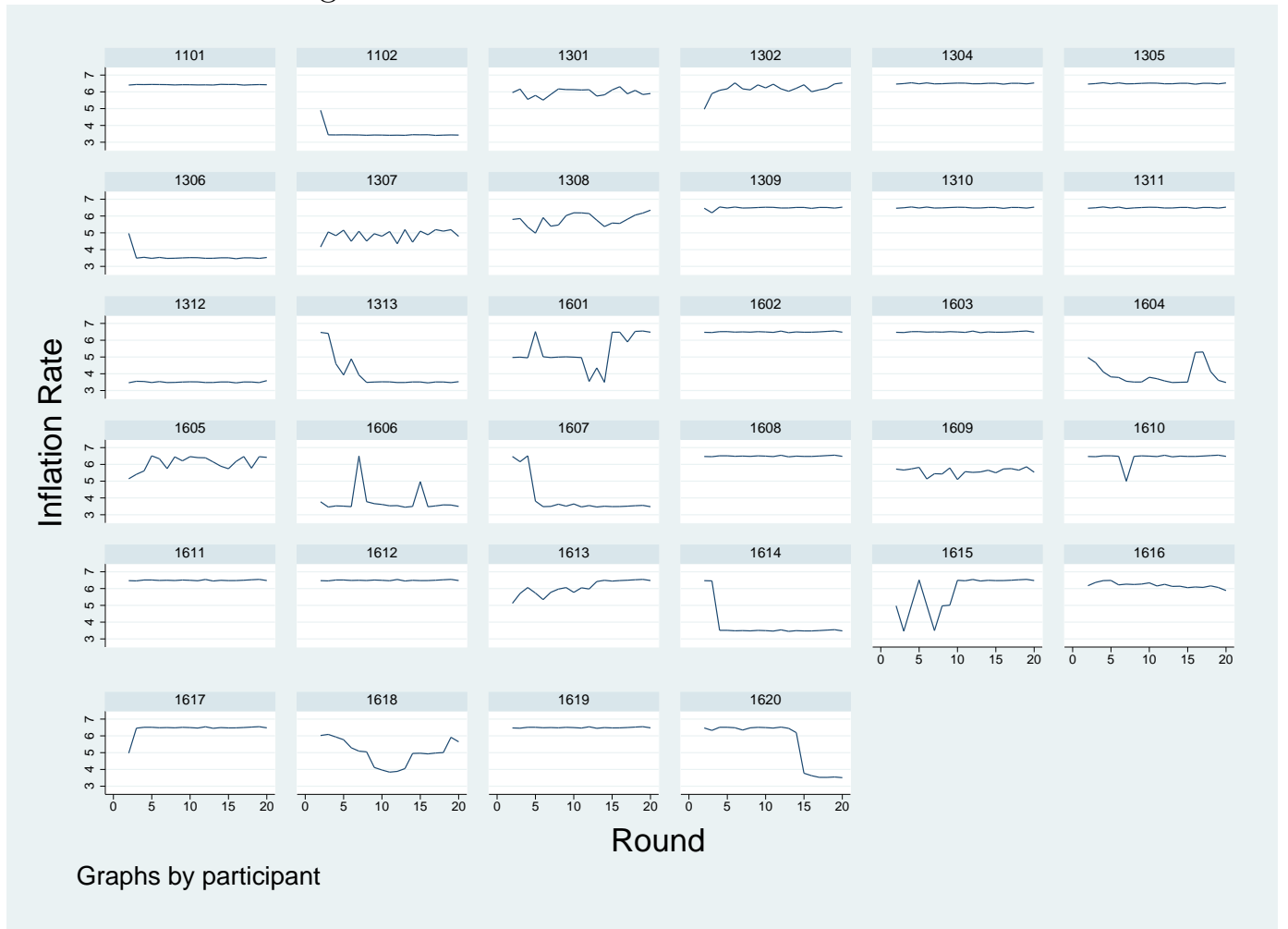


Figure C.3: Inflation Rates in Treatment LI2

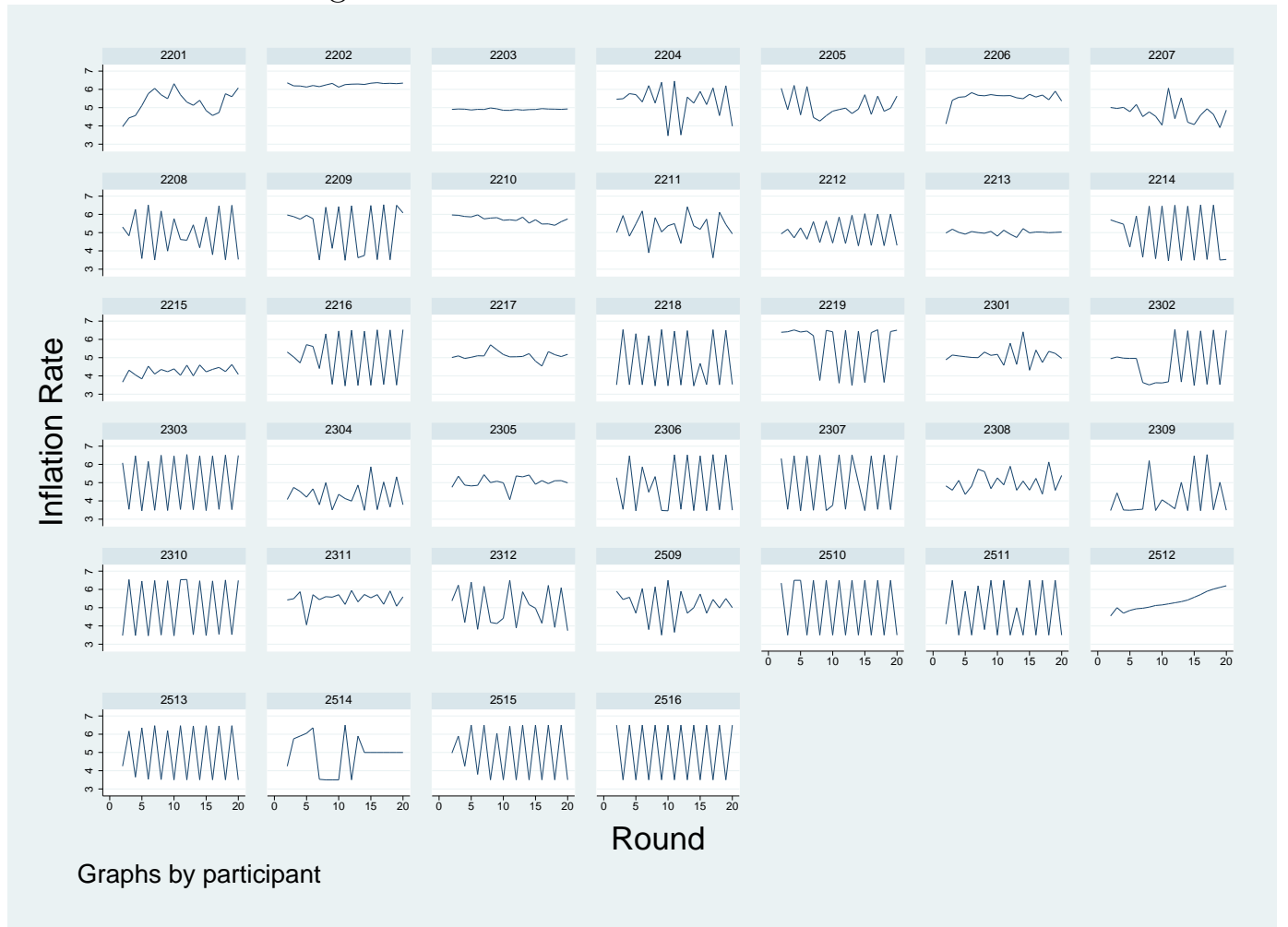


Figure C.4: Inflation Rates in Treatment LI05

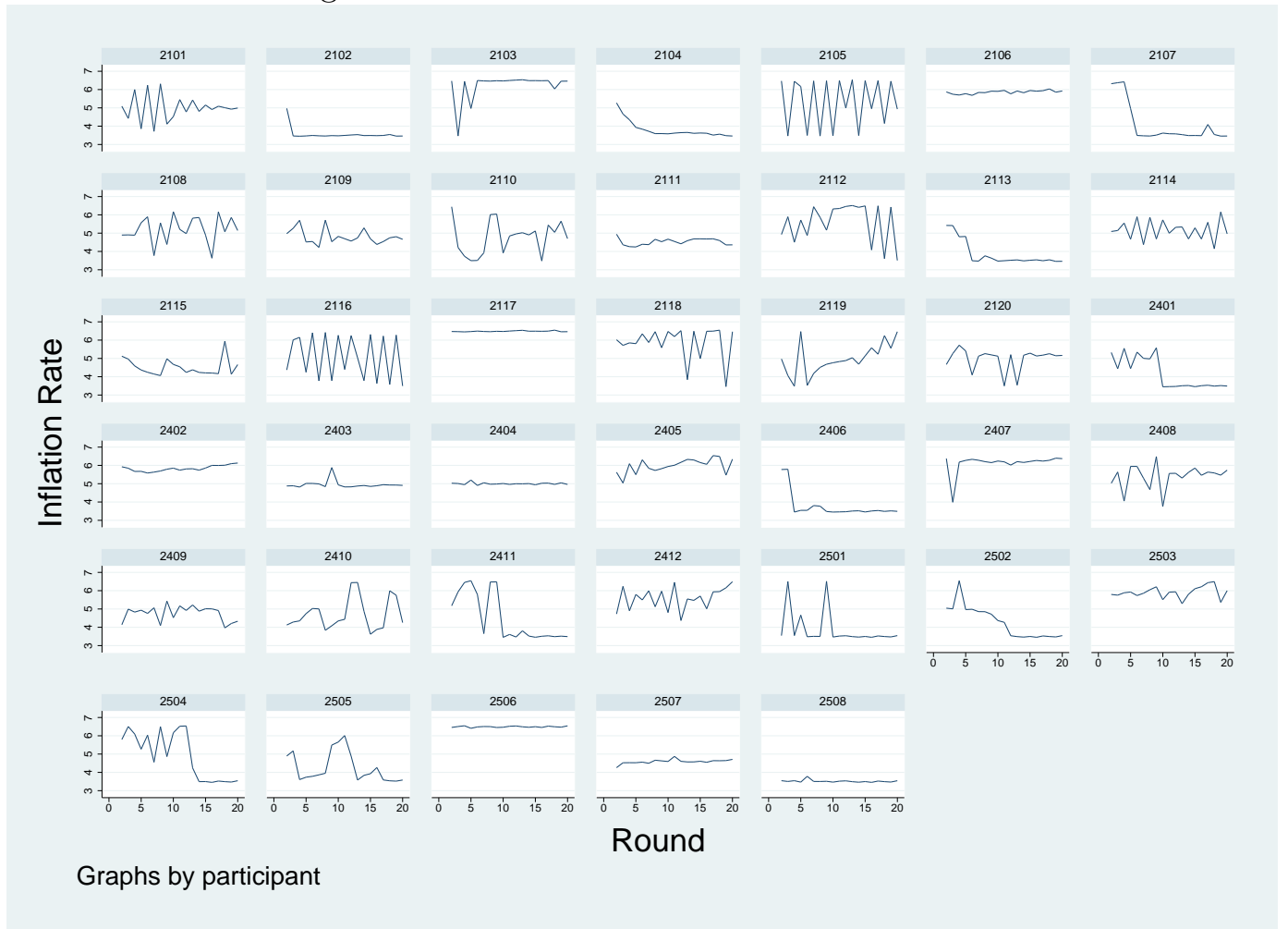

